\title{
EPIDEMIOLOGICAL CHARACTERISTICS OF HOSPITALIZED CHILDREN DIAGNOSED WITH INFLUENZA DURING 2 CONSECUTIVE SEASONS IN A TERTIARY PEDIATRIC DEPARTMENT
}

A.Kotsia1 ${ }^{1}$ I. Farakla1 ${ }^{1}$, M. Detsis 3 , M. Matsas ${ }^{2}$, M. Galetselli1 ${ }^{1}$ A. Michos ${ }^{3}$

${ }_{1} 2^{\text {nd }}$ Department of Pediatrics, Pediatric Hospital of P. \& Agl. Kyriakou, Athens, Greece 